Artikel

Issue

Issue / Series / Title

PsychoPraktijk

Issue / Series / Volume Nr

5

Issue / Date

2010

Issue / Pages / First Page

Issue / Pages / Last Page

\title{
Training van werkgeheugen en inhibitie bij kinderen en adolescenten met obesitas
}

Obesitas bij kinderen is de afgelopen decennia sterk toegenomen. Er is een aantal redenen om te interveniëren bij obesitas op de kinderleeftijd. Cardiovasculaire risicofactoren komen bij ernstige obese kinderen veel vaker voor dan bij kinderen zonder gewichtsproblemen en obesitas op de kinderleeftijd vergroot het risico op cardiovasculaire morbiditeit en mortaliteit op volwassen leeftijd (1). Bovendien zijn de psychosociale gevolgen van obesitas vaak aanzienlijk en hinderen ze het kind in zijn ontwikkeling (2). Preventie en behandeling zijn vereist, maar de resultaten zijn wisselend en eerder zwak met een grote kans op herval.

door Sandra Verbeken, Caroline Braet, Sebastiaan Dovis, Albert Ponsioen, Pier J. M. Prins, Esther ten Brinck \& Saskia van der Oord 
Sandra Verbeken en Caroline Braet zijn beiden als obesitasonderzoekers verbonden aan de Universiteit Gent (Sandra.Verbeken@UGent.be). Daarnaast zijn zij werkzaam in universitair psychologisch centrum Kind \& Adolescent, een ambulant centrum voor kinderen en jongeren. Sebastiaan Dovis, Albert Ponsioen, Pier J. M. Prins, Esther ten Brinck, \& Saskia van der Oord waren verbonden aan de Universiteit van Amsterdam tijdens de ontwikkeling van het Braingame project. Momenteel is Saskia van der Oord verbonden aan de KU Leuven.

De huidige behandelprogramma's voor overgewichtsproblemen richten zich in essentie op het geven van algemeen voeding- en bewegingsadvies aan de jongere en hun ouders met als doel een herstel van de innameverbruikbalans. Maar aangezien niet iedereen in eenzelfde voedselomgeving dik wordt, kan men ervan uitgaan dat individuele kindfactoren een rol spelen in de regulatie van de energiebalans. Er is daarom naast de bestaande globale aanpak behoefte aan nieuwe behandelprogramma's die focussen op individuele kwetsbaarheidfactoren op jonge leeftijd (3).

Impulsiviteit is een individuele factor waarbij de link met obesitas duidelijk werd aangetoond. Onderzoekers vonden dat sommige kinderen met obesitas een hoge mate van impulsiviteit vertonen in vergelijking met kinderen met een gemiddeld gewicht. Kinderen met obesitas in een residentiële setting voor behandeling van hun overgewicht zijn meer impulsief en hyperactief en minder aandachtig dan de controle kinderen (4). Bovendien blijken kinderen met overgewicht minder in staat tot uitstel van behoeftebevrediging. Ze kiezen vaker voor de kleine onmiddellijke beloning boven de uitgestelde grote beloning (5). Daarenboven werd in longitudinaal onderzoek aangetoond dat een lage impulscontrole op 
jonge leeftijd een significante predictor is van gewichtstoename op latere leeftijd (6). Bijzonder relevant is het onderzoek dat kon aantonen dat impulsiviteit bij kinderen gewichtsafname in therapie bemoeilijkt en de kans op herval vergroot (7). Dit betekent enerzijds dat kinderen die meer impulsief zijn het moeilijker hebben om te weerstaan aan de verleiding van smakelijk voedsel waardoor ze kwetsbaar zijn voor gewichtstoename en anderzijds dat impulsiviteit het hen moeilijk maakt om die gewichtstoename weer te verliezen.

Impulsiviteit is een multidimensioneel concept waarbij algemeen aangenomen wordt dat er twee belangrijke dimensies van invloed zijn, namelijk beloningsgevoeligheid en inhibitie (8). Beloningsgevoeligheid kan gedefinieerd worden als individueel verschil in de mate waarin iemand geactiveerd wordt door de aanwezigheid van beloningen en toenaderingsgedrag gaat vertonen. Inhibitie is een executieve functie en dient om op de rem te staan en afleidingen te kunnen weerstaan. Executieve functies zijn hersenfuncties die helpen bij het vasthouden en richten van de aandacht, het plannen en organiseren, sturen en controleren van gedrag. We hebben ze dan ook nodig bij alles wat we doen. Aan de hand van goed gevalideerde gedragsmaten werden deze dimensies bij kinderen met obesitas bestudeerd: er werd gevonden dat in vergelijking met kinderen met een gemiddeld gewicht kinderen met overgewicht zowel een hogere beloningsgevoeligheid vertonen als een verminderde vermogen tot inhibitie (9). Deze resultaten zijn in lijn met de recente duale procesmodellen van gedragsregulatie (10). Volgens deze modellen is effectieve gedragsregulatie slechts mogelijk indien de inhibitie controle (gericht op lange termijn doelen) in staat is om de beloningsprocessen (gericht op korte termijn bevrediging) te onderdrukken. 
Klinisch is het dan ook bijzonder relevant om na te gaan of een toename in de capaciteit tot inhibitie invloed heeft op de beloningsgevoeligheid ten aanzien van voedsel. Dit zou kinderen kunnen helpen om te weerstaan aan de smakelijke suiker- en vetrijke snacks die overal te verkrijgen zijn en om lange termijn doelen van gezondheid en slankheid na te streven.

\section{Trainen van inhibitie}

Alvast één Nederlandse studie toonde aan dat het trainen van de inhibitie een effectieve strategie kan zijn om mensen te helpen controle te krijgen over hun eetgedrag (11). In een experimenteel onderzoek werd een groep van 'chocoladeaddicts' onderworpen aan een korte inhibitietraining, een andere groep niet. $\mathrm{Na}$ afloop van de training at de inhibitie-groep significant minder chocolade tijdens een smaaktest. Deze training was specifiek gericht op de inhibitie voor chocolade, maar aangezien onderzoek aantoont dat de initiële kwetsbaarheidsfactor voor gewichtstoename een algemene beloningsgevoeligheid is, eerder dan een voedselspecifieke gevoeligheid (12), lijkt het zinvol om kwetsbare kinderen een langdurige algemene inhibitietraining te laten volgen. Op deze manier kan ook nagegaan worden of een dergelijke training ook klinisch als behandeling kan gebruikt worden.

Het vermogen tot inhibitie wordt mede bepaald door de capaciteit van het werkgeheugen. Het werkgeheugen is een executieve functie nodig voor het vasthouden van informatie bij een taak. Onderzoek bij kinderen met ADHD - ook impulsieve kinderen met lage inhibitie capaciteit en hoge beloningsgevoeligheid toont dat het werkgeheugen kan verbeteren door herhaalde training, met als gevolg een significante toename in het vermogen hun gedrag te kunnen inhiberen en bovendien een afname van impulsief gedrag zoals gerapporteerd 
door de ouders. Ook suggereren onderzoeksresultaten een lange termijn effect van deze werkgeheugentraining. De significante positieve effecten zoals gerapporteerd door de ouders waren vijf maanden na de training onveranderd (13). Ook bij kinderen met werkgeheugenproblemen (zonder ADHD) werden positieve effecten gevonden op de getrainde werkgeheugen functie en op gerelateerde EF-maten zoals inhibitie. Belangrijker is dat de training ook bij deze kinderen resulteerde in een duidelijke verbetering van het daadwerkelijke gedrag (13).

De onderzoeksgroep van Klingberg zette als eerste de stap naar de klinische behandelpraktijk met de ontwikkeling van een computer-behandelprogramma, Cogmed (14). Het is een werkgeheugentraining dat oorspronkelijk ontworpen werd voor de behandeling van kinderen met ADHD. De Universiteit van Amsterdam heeft deze toepassing verder uitgebreid met andere domeinen van executief functioneren, met name inhibitie controle en cognitieve flexibiliteit. Daarenboven werd gezocht naar mogelijkheden om impulsieve kinderen te motiveren om de saaie trainingstaken te volbrengen. Daartoe bestudeerde men gaming bij kinderen met ADHD. Men vond dat deze kinderen zich beter kunnen concentreren op een training en deze ook goed kunnen volhouden wanneer de taak is ingebed in een computerspel (15). Daarom werd door de Universiteit van Amsterdam 'Braingame Brian' ontwikkeld. Deze training wordt door de Universiteit van Gent recent onderzocht bij kinderen met obesitas in een residentiële setting. In wat volgt wordt Braingame Brian toegelicht.

\section{Braingame Brian}

Op basis van de hoger vermelde wetenschappelijke bevindingen werd de executieve functie training Braingame Brian ontworpen door de Task Force ADHD 
\& Computer (16). De trainingstaken en de spelwereld daarrond werden met veel aandacht voor motivatie ontwikkeld. Het resultaat is een mooie spelwereld waardoor kinderen constant uitgedaagd worden om de trainingstaken zo goed mogelijk uit te voeren en waarbij ze onmiddellijk beloond worden voor hun trainingsarbeid. De game-elementen bestaan uit een verhaallijn, identificatie met de hoofdpersoon, animatiefilmpjes, een duidelijk doel, en de mogelijkheid rond te lopen met de hoofdpersoon in de fictieve spelwereld (zie ook kader 1 ). Zoals hoger aangegeven zijn ook bij kinderen met obesitas inhibitiecontrole en indirect het werkgeheugen van belang. Vandaar dat het ons ook zinvol lijkt bij deze kinderen juist deze functies te trainen met bijvoorbeeld Braingame Brian.

\section{Braingame Brian een trainingsspel voor kinderen tussen de 8 en 13 jaar}

Braingame Brian is een executieve functietraining met game elementen: .

- De trainingstaken zijn onderdeel van één spelwereld.

- De hoofdpersoon is Brian die met zijn robot door verschillende werelden loopt.

- Om opdrachten te kunnen voltooien moet Brian trainingsarbeid verrichten.

- Er worden drie functies getraind: Werkgeheugen, Inhibitie, en Cognitieve Flexibiliteit (niet in de obesitasstudie)

- Er zijn in totaal 25 sessies van elk 45 minuten, waarbij het kind liefst thuis op de computer één sessie per dag afwerkt

- $\quad$ Elke sessie bestaat uit trainingsblokken van de taken van elk ongeveer 15 $\min$.

- In elke sessie heeft het kind tijd om de spelwereld te verkennen. 
- De spelwereld begint in een dorp en breidt zich uit naar andere spelwerelden waartoe Brian toegang krijgt als hij de training goed doorloopt.

- Elk voltooid blok van taken resulteert in een verandering in de spelwereld: problemen worden opgelost met behulp van door Brian bedachte machines, die zichtbaar worden na elke training.

- Hoe verder in het spel hoe meer personages verschijnen in de spelwereld en hoe blijer ze worden.

- Individueel trainingsniveau past zich aan aan het prestatieniveau van het kind.

\section{Eerste evaluatie van het project}

In het voorjaar 2011 werden 44 kinderen met obesitas met een leeftijd tussen de 8-14 jaar random toegewezen aan gecomputeriseerde training bovenop een bestaand obesitas programma ofwel aan een controlegroep die enkel de 'Care as Usual' kreeg. De kinderen moesten gedurende 25 opeenvolgende schooldagen een training sessie op een computer doorlopen die per dag ongeveer 45 minuten duurde. De totale trainingstijd liep op tot 14.58 uur. Kinderen met obesitas hebben vaak motivatieproblemen voor langdurige taken. Ondanks de motiverende factor van gaming in Braingame Brian werd op motivatieproblemen geanticipeerd door middel van het instellen van beloningssystemen. Kinderen werden beloond voor het volbrengen van iedere sessie, waarna zij konden sparen voor een beloning. Toch vielen twee kinderen uit. Een voorzichtige vergelijking van de voormeting met de nameting laat zien dat op een aantal parameters die 
peilen naar beloningsgevoeligheid de controlekinderen blijven stijgen terwijl de kinderen die de training doorliepen stabiel blijven terwijl hun prestaties op het vlak van werkgeheugen verbeterden in tegenstelling tot de controlegroep. Of dit hen kan helpen tot inhibitie van hun (eet)gedrag kan nog niet voorspeld worden. De bevindingen zullen evenwel slechts duidelijk worden tijdens de follow-up fase waarbij verwacht wordt dat die kinderen die de training doorliepen beter in staat zijn tot behoud van hun gewichtsverlies.

\section{Tot slot}

Het blijft belangrijk om behandelingprogramma's voor kinderen met overgewicht te verbeteren en steeds meer aan te passen aan de individuele kwetsbaarheden van het individu. Voor impulsieve kinderen die kwetsbaar zijn voor extern eten en gewichtstoename dient er naast de noodzakelijke aandacht voor voedselinname en beweging, ook aandacht te zijn voor de onderliggende inhibitie moeilijkheden. Mogelijk kunnen deze onderliggende kwetsbaarheden zoals inhibitie controle bij deze kinderen ook getraind worden. De vraag blijft echter of het trainen van deze onderliggende mechanismen ook zorgt voor daadwerkelijk gedragsverandering met betrekking tot hun eetpatroon. De huidige resultaten zijn nog voorlopig en replicatie is zeker noodzakelijk, toch kan de hier voorgestelde nieuwe behandelvorm aanvullend therapeutisch zinvol zijn voor kinderen met overgewicht.

\section{Noten}


(1) Faith MS ea (2001) Behavioral treatment of childhood and adolescent obesity: Current status, challenges, and future directions. In Thompson JK \& Smolak (eds) Body image, eating disorders, and obesity in youth: Assessment, prevention, and treatment (pp. 313-339). Washington, DC: American Psychological Association

(2) Puder JJ \& Munsch S (2010) Psychological correlates of childhood obesity. International journal of obesity 34 : S37-S43

(3) Wilfley DE ea (2010) Family-based bahvioral interventions. In Freemark M (ed) Pediatric obesity: Etiology, pathogenesis, and treatment (Vol. 1). New York: Humana Press

(4) Braet C ea (2007) Impulsivity in overweight children. European child and adolescent psychiatry 16: 473-483; Nederkoorn C ea (2006) Why obese children cannot resist food: The role of impulsivity. Eating behaviour 7: 315-322 (5) Bonato DP \& Boland FJ ( 1983) Delay of gratification in obese children. Addictive behaviour 8: 71-74; Verbeken S ea (in prep.) Delay of gratification in overweight children and adolescents.

(6) Francis LA \& Susman EJ (2009) Self-regulation and rapid weight gain in children from age 3 to 12 years. Archives of pediatrics \& adolescent medicine 136: 297-302; Seeyave DM ea (2009) Ability to delay gratification at age 4 years and risk of overweight at age 11 years. Archives of pediatrics $\&$ adolescent medicine 163: 303-308; Graziano PA ea (2009) Toddler self-regulation skills predict risk for pediatric obesity. International journal of obesity 34: 633-641 (7) Nederkoorn C ea (2007). Impulsivity predicts treatment outcome in obese children. Behaviour research and therapy 45: 1071-1075 
(8) Nigg JY (2000) On inhibition/disinhibition in developmental psychopathology: Views from cognitive and personality psychology and working inhibition taxonomy. Psychological bulletin 126: 220-246

(9) Nederkoorn ea (2006), zie noot 4; Verbeken S ea (2009) Childhood obesity and impulsivity: An investigation with performance-based measures. Behaviour change 3: 153-167

(10) Starck F \& Deutsch R (2004) Reflective and impulsive determinants of social behaviour. Personality and social psychology review 8: 220-247

(11) Houben K \& Jansen A (2011) Training inhibitory control; A recipe for resisting sweet temptations. Appetite 56: 345-349

(12) Stice E ea (2011) Youth at risk for obesity show greater activation of striatal and somatosensory regions to food. The journal of neuroscience 31: 4360-4366

(13) Klingberg T (2010) Training and plasticity of working memory. Trends in cognitive science $14: 317-324$

(14) Klingberg T ea (2005) Computerized training of working memory in children with ADHD - a randomized, controlled trial. J ournal of the American academy of child \& adolescent psychiatry 44: 177-186

(15) Prins JM ea (2011) Does computerized working memory training with game elements enhance motivation and training efficacy in children with ADHD? Cyberpsychology, behavior, and social networking 14: 115-122

(16) De taakgroep bestaat uit prof. Dr. P. Prins (UvA), dr. A. Ponsioen en drs. E. ten Brink (beiden Lucertis Kinder en Jeugdpsychiatrie Noord-Holland) en drs S. Dovis, dr H. Geurts en dr. S. van der Oord (allen van de UvA), in samenwerking met H. de Groot van multimediabedrijf Shosho 